\title{
UTILIZAÇÃO DE REDES NEURAIS ARTIFICIAIS NA DETERMINAÇÃO DO COEFICIENTE DE INFLUÊNCIA PARA CARREGAMENTOS TRIANGULARES E TRAPEZOIDAIS
}

\author{
Luiz Biondi Neto ${ }^{1}$ \\ Ana Cristina Castro F. Sieira ${ }^{1}$ \\ Eduardo Vidal Cabral ${ }^{1}$ \\ Juliano Lima de Lima ${ }^{1}$
}

\begin{abstract}
Resumo: O presente trabalho investiga uma aplicação de Redes Neurais Artificiais (RNAs), na determinação dos acréscimos de tensões induzidas em um ponto qualquer do maciço de solo devido à aplicação de sobrecargas triangulares ou trapezoidais na superfície. Normalmente esse processo é realizado graficamente através da obtenção de um coeficiente de influência, que permite quantificar a parcela de um carregamento aplicado na superfície, que é transmitida a um ponto no interior do maciço de solo. O objetivo dessa pesquisa consiste na utilização de RNAs para a determinação desse coeficiente eliminando-se o uso dos ábacos que relacionam a profundidade e o afastamento do ponto em relação à superfície com o acréscimo de tensão correspondente. Estes ábacos são constituídos por uma família de curvas isóbaras, formando um bulbo de tensões induzidas. A RNA usada na pesquisa foi o Perceptron de múltiplas camadas (PMC), implementado com o algoritmo de Levenberg-Marquardt (LM), uma variação do método Gauss-Newton. Os resultados obtidos pela RNA apresentaram um erro percentual máximo na faixa de 5\%, fato que habilita a sua utilização em projetos de engenharia geotécnica, porém o diferencial dessa pesquisa foi a rapidez e a facilidade na obtenção dos resultados desejados.
\end{abstract}

Palavras-Chave: Redes Neurais Artificiais, Coeficiente de Influência, Acréscimos de Tensão, Mecânica dos Solos.

Abstract: The present work investigates an application of Artificial Neural Networks (ANNs), in the determination of the stresses induced in any point of the solid of soil due to the application of trapezoid or triangular overloads in the surface, usually accomplished graphically through the influence coefficient of the shipment in the soil. The objective of that research was to use an ANN in the determination of that coefficient being eliminated, definitively, the use of the abacus that relate the depth and the removal with the pressure increment corresponding of a family of isobaric curves, denominated of bulb of induced tensions. The ANN used in the research was a Multiple Layers Perceptron (MLP), implemented with the Levenberg-Marquardt (LM) algorithm, a variation of the GaussNewton method. The results obtained by ANN presented an error percentage around of $5 \%$, fact that enables her use in projects in geotechnical engineering. However the differential of that research was the speed and the easiness in the obtaining of the wanted results.

Key-Words: Artificial Neural Networks, Influence Coefficient, Stresses Induced, Soil Mechanics.

\footnotetext{
1 Programa de Pós Graduação em Engenharia Civil, PGECIV, UERJ, Faculdade de Engenharia FEN/UERJ,

luizbiondi@terra.com.br
} 


\section{INTRODUÇÃO}

O conhecimento das tensões atuantes em um maciço de solo sejam elas devido ao peso próprio, ou proveniente de um carregamento em superfície é de suma importância no entendimento do comportamento de praticamente todas as obras de Engenharia Geotécnica. Nos solos ocorrem tensões devidas ao peso próprio e a carregamentos externos.

O solo ao sofrer solicitações se deforma, modificando o seu volume e forma inicial. A magnitude das deformações irá depender de suas propriedades elásticas e plásticas e do carregamento a ele imposto.

As estruturas de fundações exigem o conhecimento de muitas variáveis relacionadas ao solo local tais como, granulometria, plasticidade, umidade natural, consistência e compacidade, resistência, compressibilidade, expansividade, agressividade e situação do nível d'água. Além disso, faz-se necessário avaliar os efeitos em estruturas adjacentes, sempre de forma a garantir economia, segurança e funcionalidade, Montoya, Messeguer e Cabré (1979).

Um local apresenta as melhores condições para a implantação de uma construção quando o solo de fundação possuir: resistência ao cisalhamento adequada, boa capacidade de carga, baixa compressibilidade. Usualmente, os parâmetros utilizados em Geotecnia são obtidos por ensaios de campo ou laboratório.

Os primeiros estudos sobre o efeito da aplicação de um carregamento na superfície de um espaço semi-infinito, linear-elástico, isotrópico e homogêneo foram realizados por Boussinesq (1885).

Aplicando as premissas básicas da Teoria da Elasticidade, Boussinesq desenvolveu formulações matemáticas que resultam na determinação da tensão em um ponto do solo, situado na profundidade $\mathrm{z}$, e afastamento $\mathrm{r}$, devido à aplicação de uma carga concentrada $\mathrm{P}$ na superfície, como indica a Figura 1.

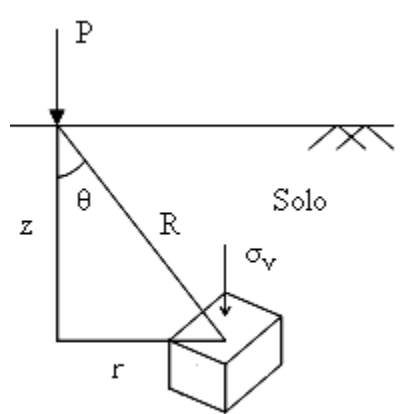

Figura 1. Tensões devido a um Carregamento Pontual na Superfície.

A expressão de Boussinesq (1) para a determinação analítica dos acréscimos de tensão vertical na profundidade $\mathrm{z}$ é a seguinte:

$$
\Delta \sigma_{\mathrm{v}}=\frac{3 \mathrm{P}}{2 \pi \mathrm{z}^{2}} \cos ^{5} \theta
$$

Esta expressão pode ser reescrita como:

$$
\Delta \sigma_{\mathrm{v}}=\frac{\mathrm{P}}{\mathrm{Z}^{2}} \cdot \mathrm{I}
$$

Com:

$$
I=\frac{3}{2 \pi} \frac{1}{\left[1+\left(\frac{r}{z}\right)^{2}\right]^{5 / 2}}
$$

Posteriormente, os estudos foram estendidos de maneira a considerar diferentes formas de carregamento distribuído na superfície do terreno. Dentre eles pode-se citar: carregamento retangular, trapezoidal, circular e triangular.

$\mathrm{O}$ presente trabalho aborda a distribuição de tensões decorrentes de carregamentos triangulares e trapezoidais distribuídos na superfície do terreno. Estes tipos de carregamento são usualmente encontrados em obras geotécnicas como: construção de aterros e barragens.

Os acréscimos de tensão em um determinado ponto da massa de solo são proporcionais à profundidade em relação ao nível do terreno e ao afastamento do eixo de simetria do carregamento.

No entanto, existem pontos que possuem o mesmo valor de acréscimo de 
tensão devido ao carregamento distribuído. O lugar geométrico destes pontos determina uma curva denominada isóbara de tensão. O conjunto de isóbaras de tensão define um bulbo de tensões.

Ressalta-se que o bulbo de tensões relaciona a profundidade (z) e o afastamento (r) com o acréscimo de tensão correspondente $\left(\Delta \sigma_{z}\right)$ para diferentes tipos de carregamento aplicados na superfície. A Figura 2 mostra um bulbo de tensões correspondente a um carregamento pontual aplicado na superfície do terreno.
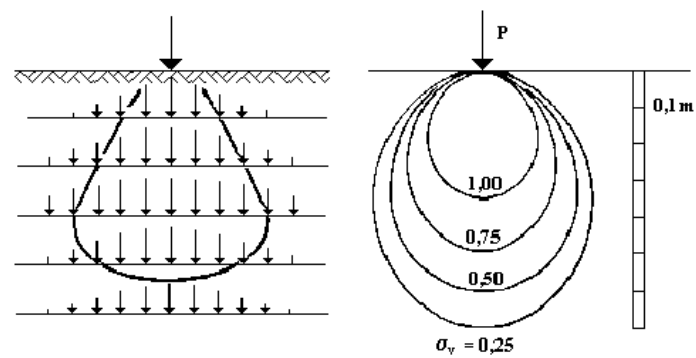

Figura 2. Bulbo de tensões: carregamento pontual.

Para a determinação das tensões induzidas decorrentes de carregamentos triangulares e trapezoidais, faz-se uso de soluções gráficas e analíticas.

As formulações que norteiam a determinação analítica dos acréscimos de tensão ao longo da profundidade são variações das expressões apresentadas por Boussinesq (1885).

Por outro lado, as RNAs têm sido utilizadas em diversas áreas do conhecimento tais como: economia, finanças, medicina, engenharia, etc., principalmente em problemas de classificação, aproximação de funções, predição, reconhecimento de padrões e controle, dentre outras.

A razão está relacionada ao fato de que uma RNA, devidamente treinada, contendo uma ou mais camadas ocultas e com um número adequado de neurônios artificiais, possa aproximar qualquer função não-linear contínua, num dado intervalo, Suykens (1996).

As RNAs são estruturas paralelas compostas de neurônios artificiais, densamente conectadas que apresentam duas fases distintas de operação: a aprendizagem (treinamento) e a execução
Zurada, J. (1992) e Haykin S. (1994).

Na aprendizagem são apresentados estímulos à entrada, denominados padrões de treinamento e pelos alvos retirados dos ábacos disponíveis para o tipo de carregamento e validado pelos especialistas da área em estudo. $\mathrm{Na}$ fase de execução, as RNAs recebem como estímulo de entrada um conjunto de padrões de testes que não fizeram parte do treinamento e apresenta os resultados.

A arquitetura utilizada foi baseada no perceptron de múltiplas camadas (MLP), Haykin S. (1994). A metodologia a ser usada no treinamento da rede MLP pode ser dividido em duas fases principais: "forward" e "backward". A primeira consiste na propagação dos estímulos apresentados à entrada para a saída. Esses estímulos fluem por toda a rede, recebendo a computação neural, camada por camada, até gerarem a saída.

A partir do resultado desejado (alvo), calcula-se um erro na camada de saída. A segunda etapa ocorre em sentido contrário.

O erro calculado é então retro propagado pelas camadas antecessoras (error-back-propagation), atualizando os pesos das conexões, Haykin S. (1994).

O algoritmo de retro propagação de erro (BP) é baseado no método do gradiente descendente, que computa as derivadas parciais de uma função de erro, com relação ao vetor peso $\mathrm{W}$ de certo vetor de entrada Zurada, J. (1992), Dayhoff, J. (1990) e Haykin S. (1994).

A regra de Widrow-Hoff é a base fundamental de diversos métodos de treinamento das RNAs, inclusive MLPs Zurada, J. (1992). Esta regra avalia o erro a cada iteração através da derivada parcial desse erro em relação ao peso.

No processo adaptativo usaremos o algoritmo de Levenberg-Marquardt, Ranganathan (2004).

No presente trabalho, a RNA será usada para a obtenção do Coeficiente de Influência I, necessário para a determinação dos acréscimos de tensão vertical em solos submetidos a carregamentos infinitos triangulares ou trapezoidais. Para cada tipo de 
carregamento (triangular ou trapezoidal) serão apresentadas as formulações analíticas baseadas na Teoria da Elasticidade, e as soluções gráficas geradas a partir destas formulações. Os resultados fornecidos pelas RNAs serão comparados aos resultados determinados pela teoria da Elasticidade.

\section{FUNDAMENTAÇÃO TEÓRICA}

\subsection{GEOTECNIA}

A compreensão do comportamento de praticamente todas as obras geotécnicas exige o conhecimento das tensões atuantes no maciço de solo.

Estas tensões podem ser decorrentes do peso próprio, ou de um carregamento aplicado na superfície do terreno.

As tensões verticais decorrentes do peso próprio são determinadas a partir do peso das camadas de solo sobrejacentes ao ponto analisado (4).

$$
\sigma_{\mathrm{v}}=\sum \gamma_{\mathrm{i}} \cdot \mathrm{z}_{\mathrm{i}}
$$

Onde: $\gamma_{\mathrm{i}}$ e $\mathrm{z}_{\mathrm{i}}$ são, respectivamente, o peso específico do solo e a espessura da camada i.

As primeiras experiências realizadas em Mecânica dos Solos mostraram que ao se aplicar uma carga na superfície do terreno, numa área bem definida, os acréscimos de tensão em certa profundidade não se limitam à projeção da área carregada.

Nas laterais da área carregada também ocorrem aumentos de tensão, que se somam às tensões decorrentes do peso próprio.

Como a somatória dos acréscimos das tensões verticais, nos planos horizontais, em qualquer profundidade, é sempre constante, os acréscimos das tensões imediatamente abaixo da área carregada diminuem à medida que a profundidade aumenta, porque a área atingida aumenta com a profundidade, Souza Pinto (2002).

$\mathrm{Na}$ Figura 3 está representada a variação dos acréscimos de tensão vertical ao longo da linha vertical, passando pelo eixo de simetria da área carregada.

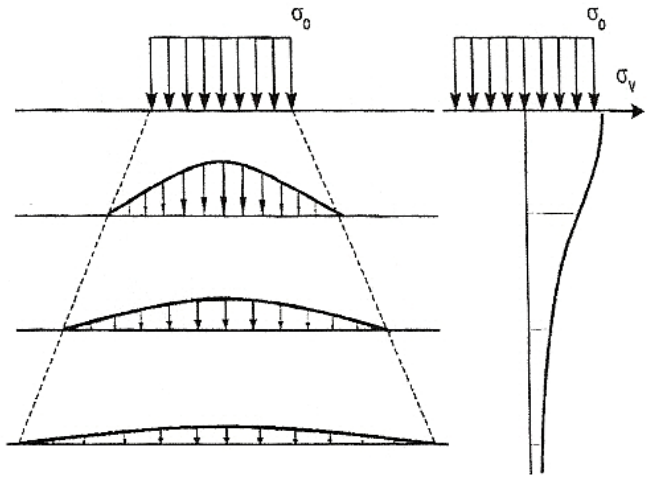

Figura 3. Distribuição de Tensões com a Profundidade.

Os itens subseqüentes apresentam as soluções analíticas e gráficas usadas na determinação dos acréscimos das tensões induzidas decorrentes de carregamentos triangulares e trapezoidais abordados nessa investigação.

\subsubsection{CARREGAMENTO TRIANGULAR}

Poulos e Davis (1974) apresentam a solução analítica para a determinação dos acréscimos de tensão vertical $\left(\Delta \sigma_{\mathrm{V}}\right)$ decorrentes de um carregamento triangular aplicado na superfície:

$$
\begin{aligned}
& \Delta \sigma_{\mathrm{V}}=\frac{\Delta \mathrm{q}}{\pi}\left[\left(\alpha_{1}+\alpha_{2}\right)+\frac{\mathrm{x}}{\mathrm{b}}\left(\alpha_{1}-\alpha_{2}\right)-\frac{\mathrm{z}}{\mathrm{b}} \ln \frac{\mathrm{R}_{1} \mathrm{R}_{2}}{\mathrm{R}_{\mathrm{o}}^{2}}\right]+ \\
& \frac{\mathrm{p} \cdot \mathrm{z}}{\pi \cdot \mathrm{b}}\left(\ln ^{2} \frac{\mathrm{R}_{1} \mathrm{R}_{2}}{\mathrm{R}_{\mathrm{o}}^{2}}+\left(\alpha_{1}-\alpha_{2}\right)^{2}\right)^{1 / 2}
\end{aligned}
$$

Onde: $\Delta \mathrm{q}, \alpha_{1}, \alpha_{2}, \mathrm{x}, \mathrm{b}, \mathrm{z}, \mathrm{R}_{0}, \mathrm{R}_{1}$ e $\mathrm{R}_{2}$ são parâmetros que representam 0 carregamento aplicado na superfície, e as inclinações e distâncias em relação ao carregamento, como indicado na Figura 4.

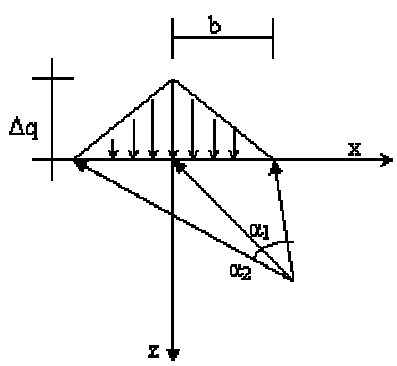

Figura 4. Carregamento triangular simétrico.

Com base na Teoria da Elasticidade (5), foi desenvolvido o ábaco apresentado na Figura 5, onde se determina, 
graficamente, o coeficiente de influência e consequentemente o acréscimo de tensão em qualquer ponto em profundidade e distante horizontalmente do carregamento distribuído triangular Poulos e Davis (1974).

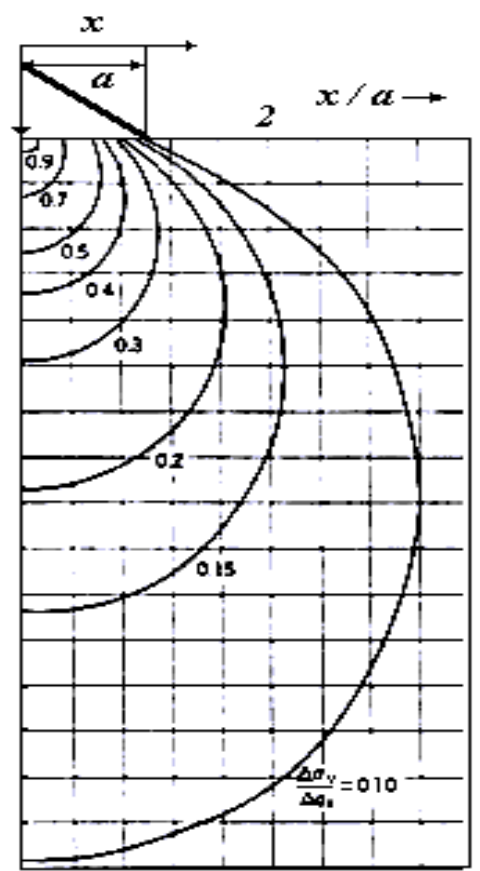

Figura 5. Solução gráfica para determinação dos acréscimos de tensão decorrentes de carregamentos triangulares.

Este acréscimo de tensão é determinado a partir do fator de influência I:

$\Delta \sigma_{\mathrm{v}}=\Delta \mathrm{q} I$

Cabe salientar que as soluções gráficas foram desenvolvidas visando facilitar a determinação dos acréscimos de tensão e definir isóbaras de tensão. No entanto, existem regiões no gráfico em que a determinação de I torna-se difícil e exige interpolação de dados. Neste sentido, as RNAs aparecem como uma ferramenta capaz de fornecer com rapidez e exatidão o valor de I.

\subsubsection{CARREGAMENTO TRAPEZOIDAL}

A Figura 6 ilustra o caso de um carregamento infinito trapezoidal, aplicado na superfície do terreno. Os acréscimos de tensão vertical devido a este tipo de carregamento podem ser determinados, analiticamente, pela equação (7):

$$
\Delta \sigma_{\mathrm{v}}=\frac{\mathrm{p}}{\pi}\left[\beta+\frac{\mathrm{x}}{\mathrm{a}} \alpha-\frac{\mathrm{z}}{\mathrm{r}^{2}}(\mathrm{x}-\mathrm{b})\right]
$$

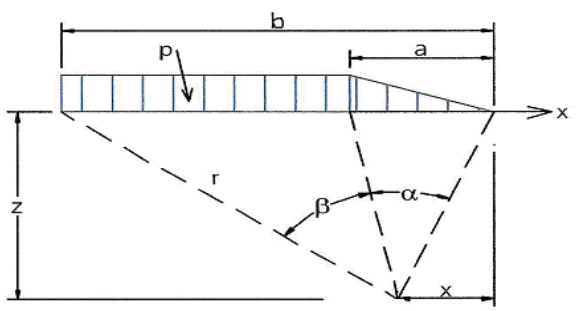

Figura 6. Acréscimo de tensão em um ponto qualquer devido a um carregamento trapezoidal.

Nos casos de carregamentos infinitos trapezoidais, considerando-se o acréscimo de tensão no eixo de simetria do carregamento, a determinação do coeficiente de influência I se dá através do Gráfico de Osterberg (1957), apresentado na Figura 7.

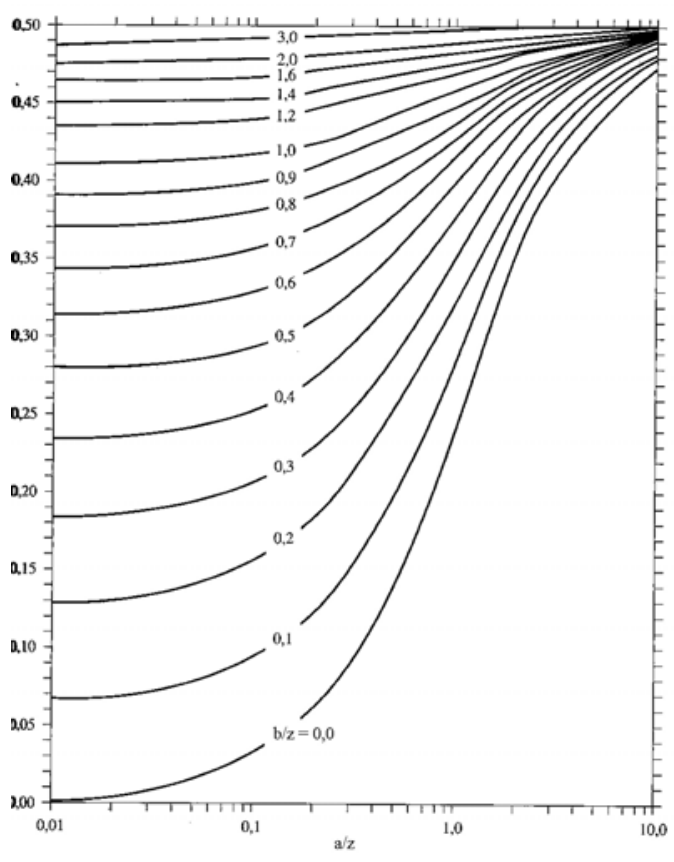

Figura 7. Gráfico de Osterberg (1957): Carregamentos Infinitos Trapezoidais.

Para determinação do acréscimo de tensão vertical para este tipo de carregamento, utiliza-se a equação:

$\Delta \sigma_{\mathrm{v}}=\mathrm{I} . \Delta \mathrm{q}$

Onde: $\Delta$ q é a sobrecarga aplicada na superfície.

O Gráfico de Osterberg permite a 
determinação do coeficiente de influência I, a partir da entrada a/z e b/z.

Ressalta-se que para carregamentos infinitos triangulares e trapezoidais, as soluções gráficas mostram-se mais otimizadas do que as soluções analíticas. No entanto, existem dificuldades de obtenção de pontos intermediários nos gráficos, que podem ser obtidos por interpolação. Nesse sentido, RNAs, com sua capacidade de generalização aparecem como uma ferramenta capaz de minimizar esta dificuldade.

O presente trabalho compara os resultados do coeficiente de influência, I, obtidos a partir das soluções gráficas, com os resultados fornecidos pelas redes neurais, considerando diferentes dimensões de carregamento e diferentes profundidades.

\subsection{ALGORITMO MARQUARDT}

LEVENBERG-

Em nossa aplicação usaremos o algoritmo Levenberg-Marquardt (LM) O método de LM utiliza treinamento em lote e consiste em um aperfeiçoamento do método Gauss-Newton, que é uma variante do método de Newton.

O método de Newton usa a informação da derivada parcial de segunda ordem do índice de desempenho utilizado para corrigir os pesos. Isso permite que além da informação do gradiente, seja usada informação sobre a curvatura da superfície do erro, Roweis, S. (2003).

O método de Newton pode ser usado para resolver a equação:

$$
\nabla \mathrm{V}(\overline{\mathrm{w}})=0
$$

Expandindo o gradiente de $\mathrm{V}$ em uma série de Taylor em torno dos pesos $\mathrm{w}_{0}$, obtemos:

$$
\nabla \mathrm{V}(\overline{\mathrm{w}})=\nabla \mathrm{V}\left(\overline{\mathrm{w}_{0}}\right)+\left(\overline{\mathrm{w}}-\overline{\mathrm{w}_{0}}\right)^{\mathrm{T}} \nabla^{2} \mathrm{~V}\left(\overline{\mathrm{w}_{0}}\right)_{+} \ldots
$$

Desprezando os termos de ordem superior a dois e resolvendo a Equação (10) em relação a $\nabla \bar{w}$ obtemos a regra de atualização de $\bar{w}$, dada pela Equação (11) ou de forma mais geral, representada pela
Equação (12).

$$
\begin{aligned}
& \nabla \mathrm{w}=-\left[\nabla^{2} \mathrm{~V}\left(\mathrm{w}_{0}\right)\right]^{-1} \nabla \mathrm{V}\left(\mathrm{w}_{0}\right) \\
& \nabla \overline{\mathrm{w}}=-\left[\nabla^{2} \mathrm{~V}(\overline{\mathrm{w}})\right]^{-1} \nabla \mathrm{V}(\overline{\mathrm{w}})
\end{aligned}
$$

Desprezando-se os termos de ordem superior do desenvolvimento em série de Taylor, assume-se uma aproximação quadrática para o gradiente.

Embora a convergência seja rápida, pode ser bastante sensível à posição inicial na superfície do erro, que é função dos valores dos pesos iniciais em $w_{0}$. O índice de desempenho $\mathrm{V}$ pode ser definido como a soma do quadrado do erro $e_{i}$, associado ao i-ésimo padrão de treinamento da rede, Equação (13).

$\mathrm{V}(\overline{\mathrm{w}})=\sum_{\mathrm{i}=1}^{\mathrm{n}} \mathrm{e}_{\mathrm{i}}^{2}(\overline{\mathrm{w}})$

Então o gradiente e o hessiano podem ser expressos como funções do jacobiano J (derivadas parciais) do índice de desempenho $\mathrm{V}$, como:

$$
\begin{aligned}
& \nabla \mathrm{V}(\overline{\mathrm{w}})=\mathrm{J}^{\mathrm{T}}(\overline{\mathrm{w}})(\overline{\mathrm{e}})(\overline{\mathrm{w}}) \\
& \nabla \mathrm{V}(\overline{\mathrm{w}})=\mathrm{J}^{\mathrm{T}}(\overline{\mathrm{w}}) \mathrm{J}(\overline{\mathrm{w}})+\mathrm{S}(\overline{\mathrm{w}})
\end{aligned}
$$

Onde:

$$
\mathrm{s}(\overline{\mathrm{w}})=\sum_{\mathrm{i}=1}^{\mathrm{N}} \mathrm{e}_{\mathrm{i}}(\overline{\mathrm{w}}) \nabla^{2} \mathrm{e}_{\mathrm{i}}(\overline{\mathrm{w}})
$$

A avaliação do hessiano pode ser extremamente complexa. Para contornar esse problema, foram propostos métodos que utilizam aproximações, denotados Quasi-Newton, dentre os quais se situam o Método de Gauss-Newton e LevenbergMarquardt.

No método de Gauss-Newton assume-se $S(\bar{w}) \approx 0$, então a regra de atualização de Newton passa a ser:

$$
\Delta \overline{\mathrm{W}}=-\left[\mathrm{J}^{\mathrm{T}}(\overline{\mathrm{w}}) \mathrm{J}(\overline{\mathrm{w}})\right]^{-1} \mathrm{~J}^{\mathrm{T}}(\overline{\mathrm{w}}) \overline{\mathrm{e}}(\overline{\mathrm{w}})
$$

O problema deste método consiste 
no fato de que a matriz $\mathrm{H}=\left[\mathrm{J}^{\mathrm{T}}(\overline{\mathrm{x}}) \mathrm{J}(\overline{\mathrm{x}})\right]$, pode não ter inversa. Para contornar essa situação, Levenberg, Hagan M. (1994) propôs somar a parcela $\mu \mathrm{I}$ a essa matriz, onde $\mu$ é um escalar e I é a matriz identidade, resultando na seguinte regra de atualização Hagan M. (1994):

$$
\Delta \overline{\mathrm{W}}=-\left[\mathrm{J}^{\mathrm{T}}(\overline{\mathrm{w}}) \mathrm{J}(\overline{\mathrm{w}})+\mu \mathrm{I}\right]^{-1} \mathrm{~J}^{\mathrm{T}}(\overline{\mathrm{w}}) \overline{\mathrm{e}}(\overline{\mathrm{w}})
$$

A matriz $\left\lfloor\mathrm{J}^{\mathrm{T}}(\overline{\mathrm{w}}) \mathrm{J}(\overline{\mathrm{w}})+\mu \mathrm{I}\right\rfloor$ sempre possuirá inversa, Roweis S. (2003).

Se o valor do índice de desempenho diminuir após a primeira atualização, o escalar $\mu$ deve ser diminuído para reduzir a influência do gradiente descendente.

Ao contrário, se o valor do índice de desempenho aumenta então a melhor escolha consiste em seguir a direção do gradiente descendente. Neste caso, o valor de $\mu$ deve ser aumentado.

Se $\mu$ tornar-se muito grande, a informação dada pela aproximação H para o hessiano não será útil no cálculo da atualização de $\bar{w}$.

Para contornar esse problema, Marquardt propôs substituir a matriz identidade pela matriz diagonal de $\mathrm{H}$, resultando na seguinte regra de atualização, Roweis S. (2003):

$$
\begin{aligned}
& \Delta \bar{w}=-\left[J^{T}(\bar{w}) J(\bar{w})+\mu \operatorname{diag}\left[J^{T}(\bar{w}) J(\bar{w})\right]^{-1} .\right. \\
& J^{T}(\bar{w}) e(\bar{w})
\end{aligned}
$$

É fundamental que o cálculo da matriz $\mathrm{J}^{\mathrm{T}}(\overline{\mathrm{W}})$ seja realizado de forma eficiente. Essa matriz é formada pelo cálculo dos gradientes, para cada padrão de treinamento apresentado à rede.

Hagan M. (1994) propôs uma modificação no algoritmo de retro propagação que permite utilizar esse algoritmo para calcular o Jacobiano.

O método LM pode ser sintetizado da seguinte forma:

1) Atribuição inicial de pesos;

2) Cálculo da atualização dos pesos de acordo com a Equação (19);
3) Avaliação do erro, propagando os padrões na rede:

- Se o erro aumentou desfaça a atualização de $\bar{w}$ e diminua $\mu$;

- Senão valide a atualização $\bar{w}$ e incremente $\mu$;

- Se convergir encerre;

- Senão volte para 2.

\section{MODELAGEM E TREINAMENTO DAS RNAS}

Foram modeladas e treinadas duas RNAs com arquiteturas distintas: uma utilizada para carregamento triangular e outra para carregamento trapezoidal.

O modelo da RNA que apresentou o melhor desempenho para o carregamento triangular foi a arquitetura com duas camadas ocultas.

A primeira camada oculta com 5 neurônios, a segunda com 15 neurônios e a saída com 1 neurônio artificial, representando o coeficiente de Influência, Figura 8.

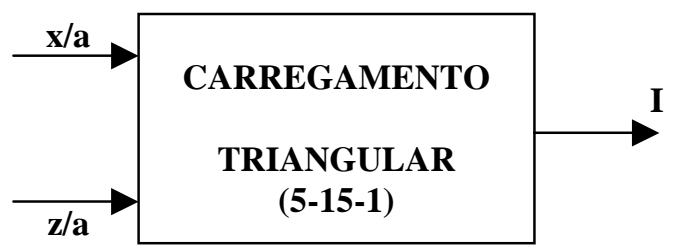

Figura 8. Modelo da RNA Carregamentos Infinitos Triangulares.

A curva de treinamento da rede relativa ao carregamento triangular é apresentada na Figura 9, mostrando a convergência para uma tolerância de erro no treinamento, de $10^{-4}$ em cerca de 30 épocas.

No caso do carregamento trapezoidal o modelo que apresentou o melhor desempenho foi a arquitetura com duas camadas ocultas. A primeira camada oculta com 10 neurônios, a segunda com 45 neurônios e a saída com 1 neurônio artificial, representando o Coeficiente de Influência, Figura 10. 


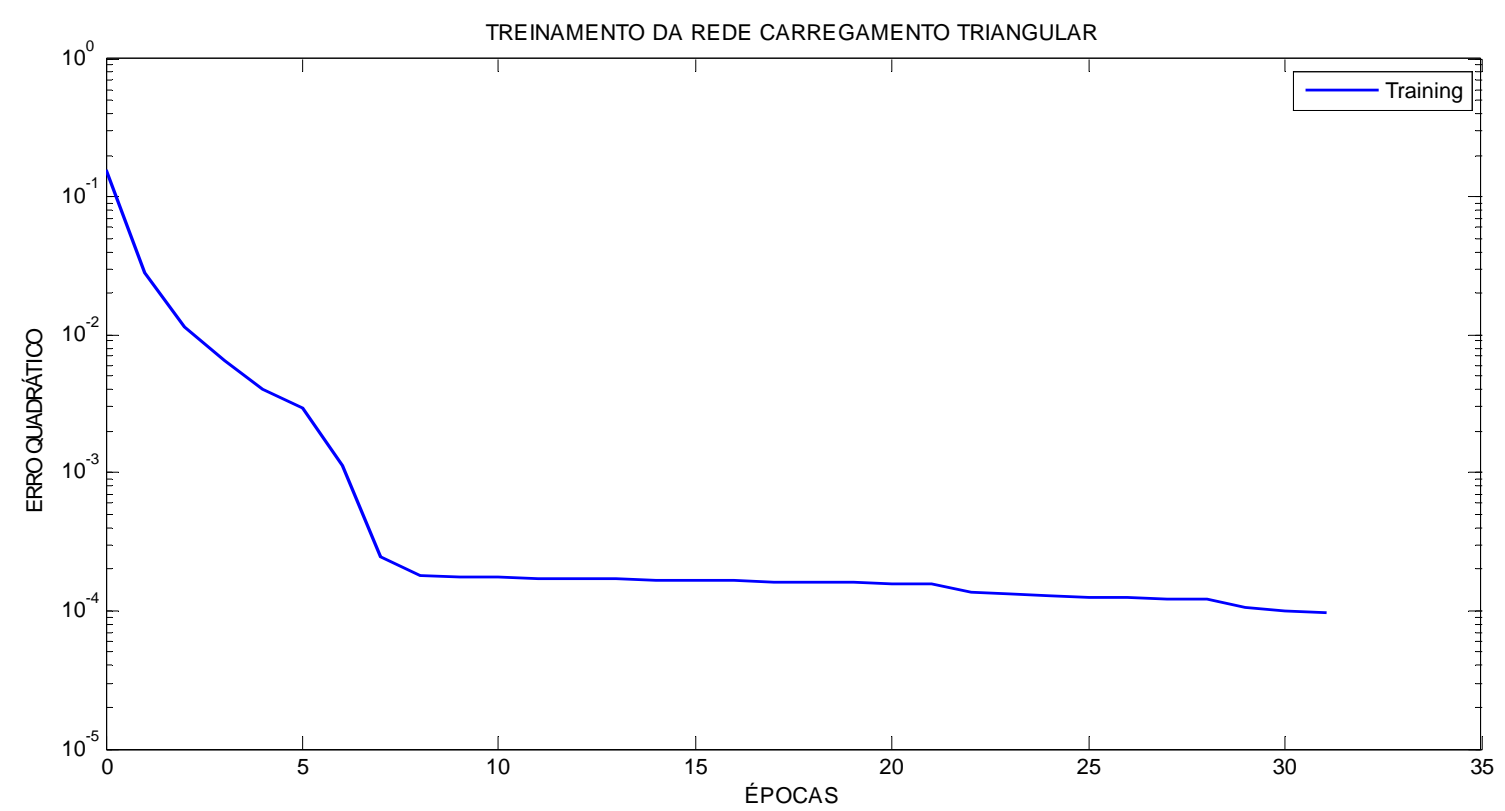

Figura 9. Curva de treinamento da RNA Carregamentos Infinitos Triangulares.

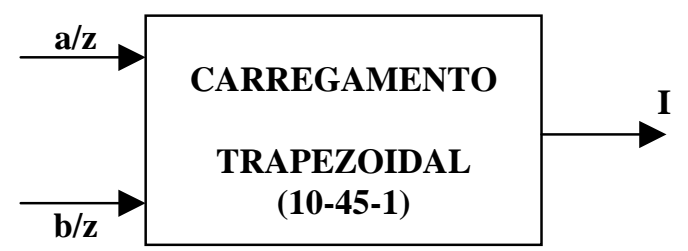

Figura 10. Modelo da RNA Carregamentos Infinitos Trapezoidais.

A curva de treinamento da rede relativa ao carregamento trapezoidal é apresentada na Figura 11, mostrando a convergência para uma tolerância de erro no treinamento, de $10^{-5}$ em cerca de 1200 épocas.

As RNAs foram treinadas, usandose o método Levenberg-Marquardt, com um banco de dados validado pelos especialistas da área e obtido diretamente dos ábacos disponíveis para os dois tipos de carregamento e apresentados nas Figuras 5 e 7.

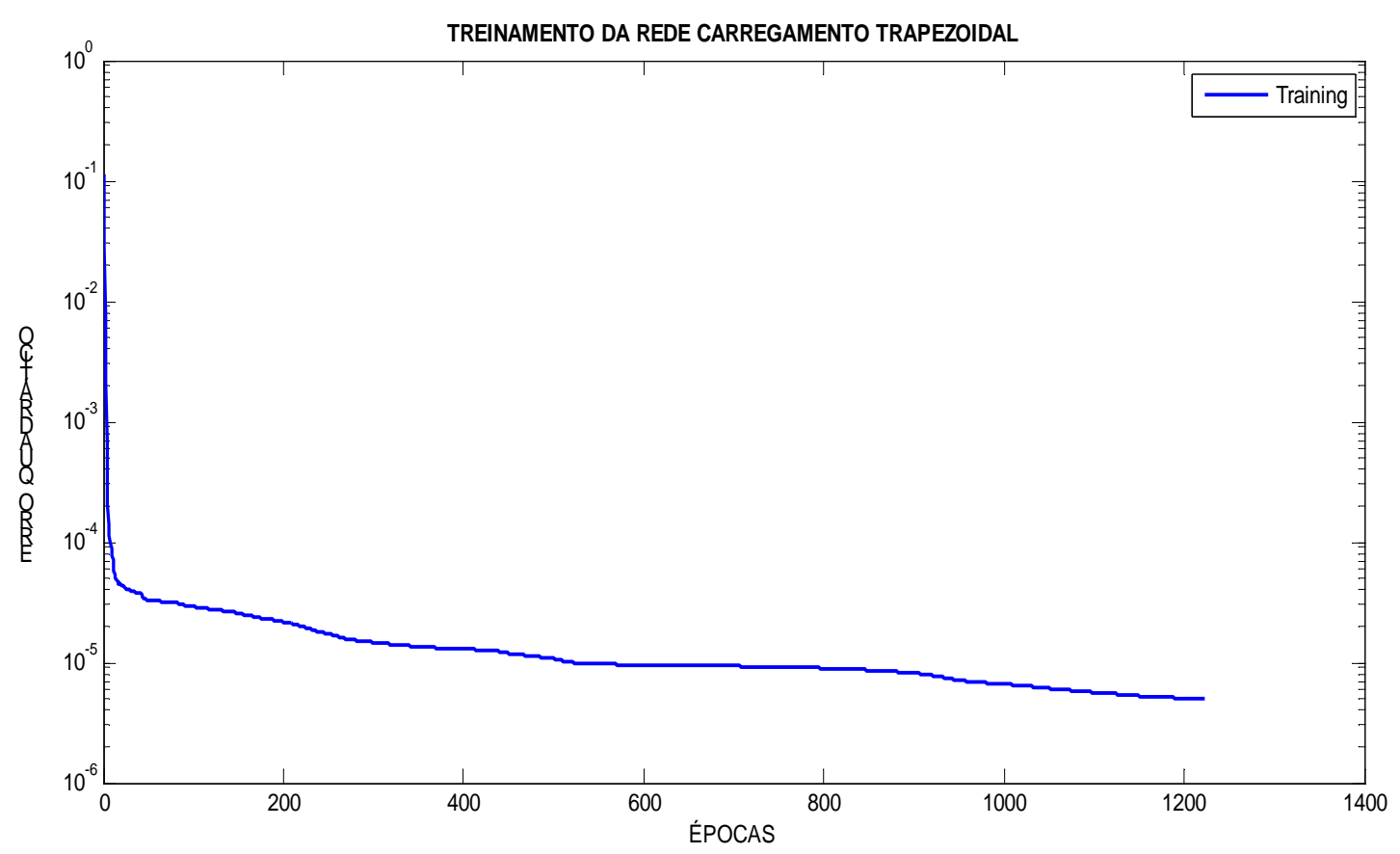

Figura 11. Curva de treinamento da RNA Carregamentos Infinitos Trapezoidais.

Para o carregamento triangular foi usado um banco de dados para treinamento composto de 98 padrões envolvendo na entrada a dimensão ( $2 \mathrm{x}$ 98) referentes aos padrões x/a e z/a e na 
saída a dimensão de $(1$ x 98) referente ao alvo, no caso o coeficiente de Influência $\mathrm{I}=\Delta \sigma_{\mathrm{v}} / \Delta \mathrm{q}$.

No caso do carregamento trapezoidal o banco de dados usado para treinamento foi composto de 477 padrões envolvendo na entrada a dimensão ( $2 \mathrm{x}$ 477) referentes aos padrões $a / z$ e b/z e na saída a dimensão de ( 1 x 477) referente ao alvo, no caso o coeficiente de Influência $\mathrm{I}=\Delta \sigma_{\mathrm{v}} / 2 \Delta \mathrm{q}$.

\section{RESULTADOS}

As RNAs foram submetidas a diversos testes, visando verificar a coerência dos seus resultados. Os padrões de teste jamais fizeram parte do treinamento. A validação dos resultados obtidos pelas RNAs foi verificada pela comparação com os resultados obtidos diretamente dos ábacos.

Nesse caso os ábacos utilizados, específicos para cada caso de carregamento estão apresentados nas Figuras 5 e 7.

A Figura 12 mostra que, para 37 testes a eficiência da RNA relativa a carregamento triangular atende as premissas da pesquisa produzindo saídas com um erro máximo na faixa de $\pm 5 \%$, Figura 13.

Para o caso relativo ao carregamento trapezoidal a Figura 14 apresenta 37 testes de eficiência da RNA nos quais pode ser observado que os mesmos atendem as premissas da pesquisa produzindo saídas com um erro máximo de cerca de $\pm 3,5 \%$, Figura 15 .

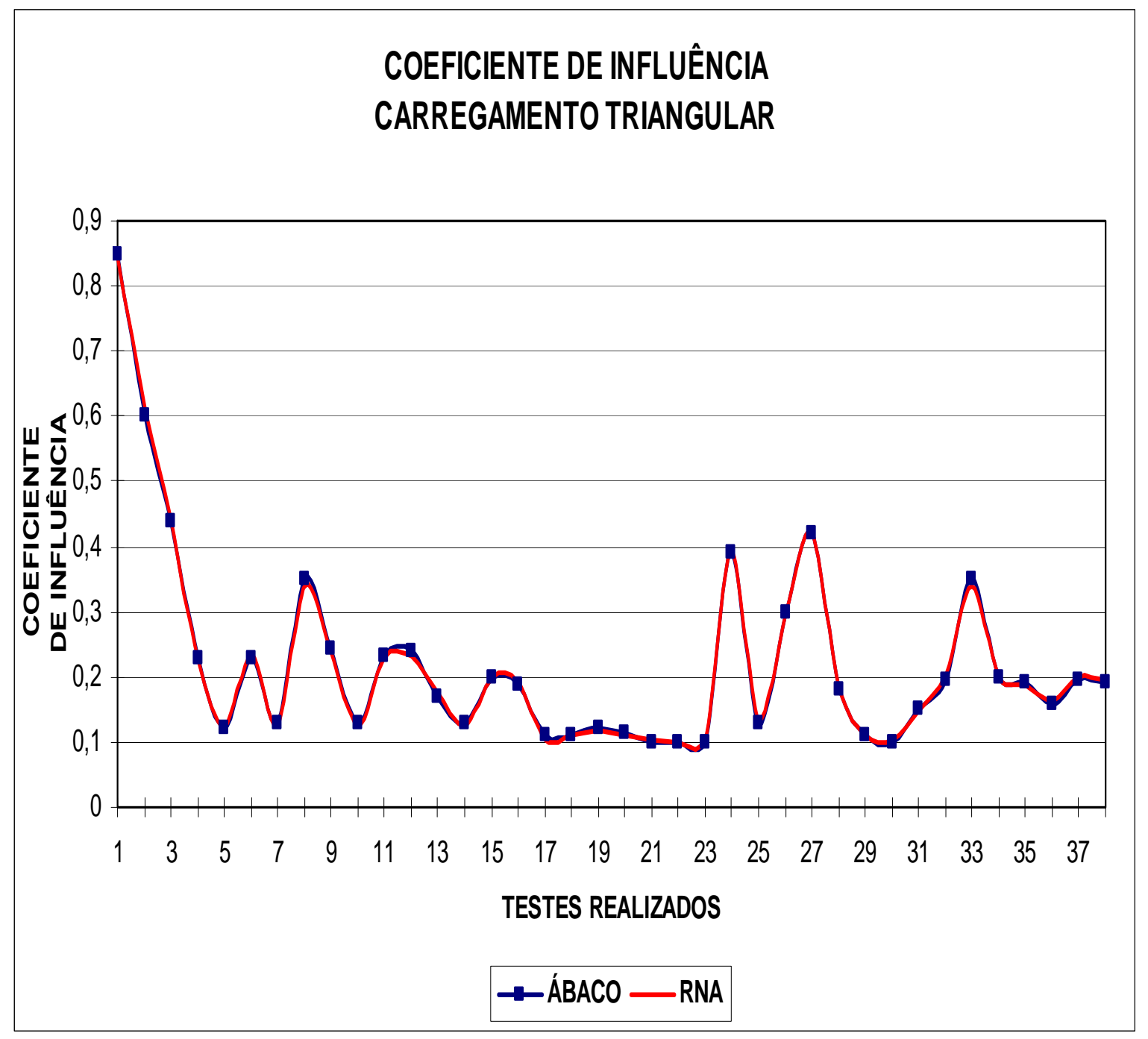

Figura 12. Resultados da RNA para Carregamentos Infinitos Triangulares. 


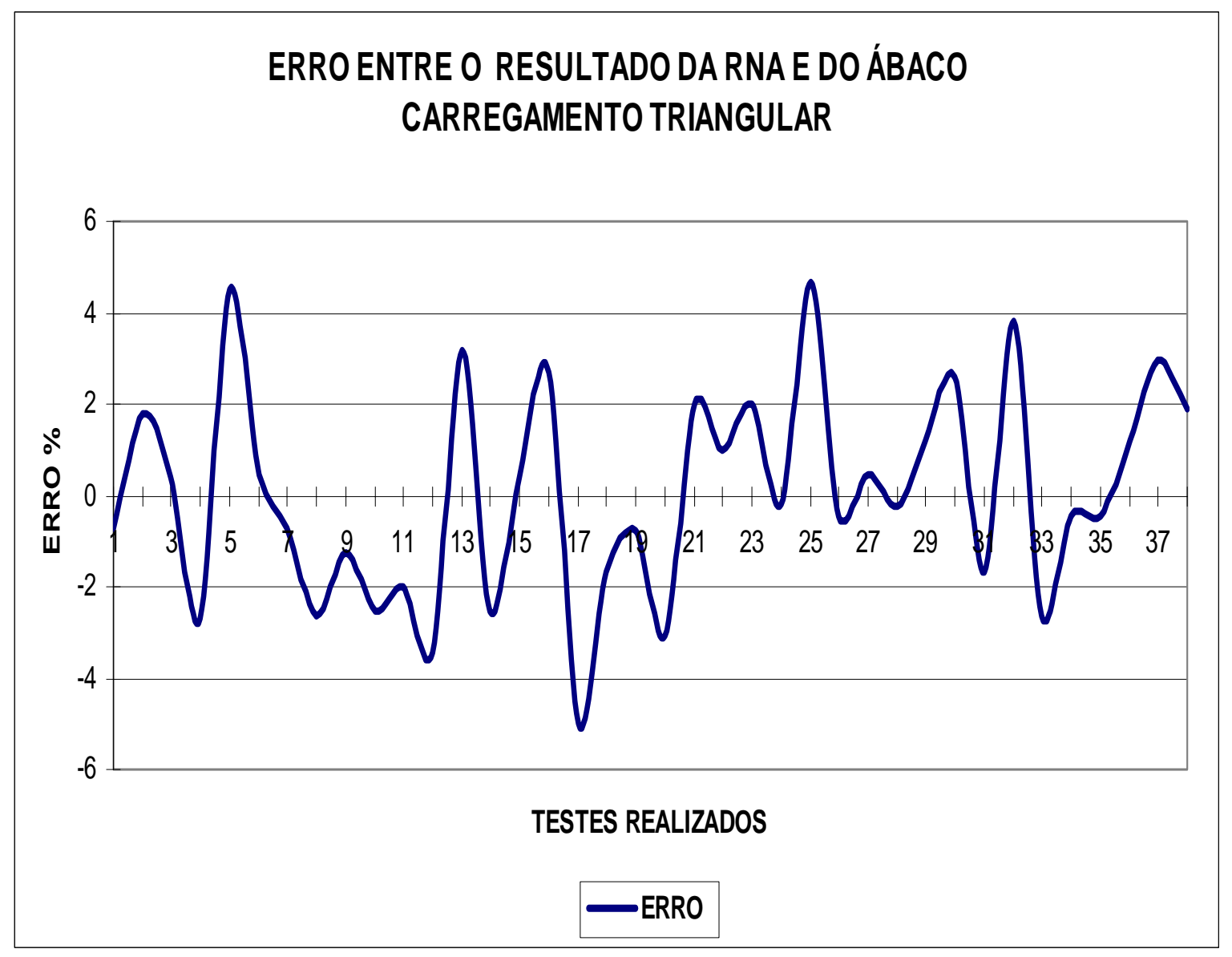

Figura 13. Erro percentual dos resultados da RNA para Carregamentos Infinitos Triangulares.

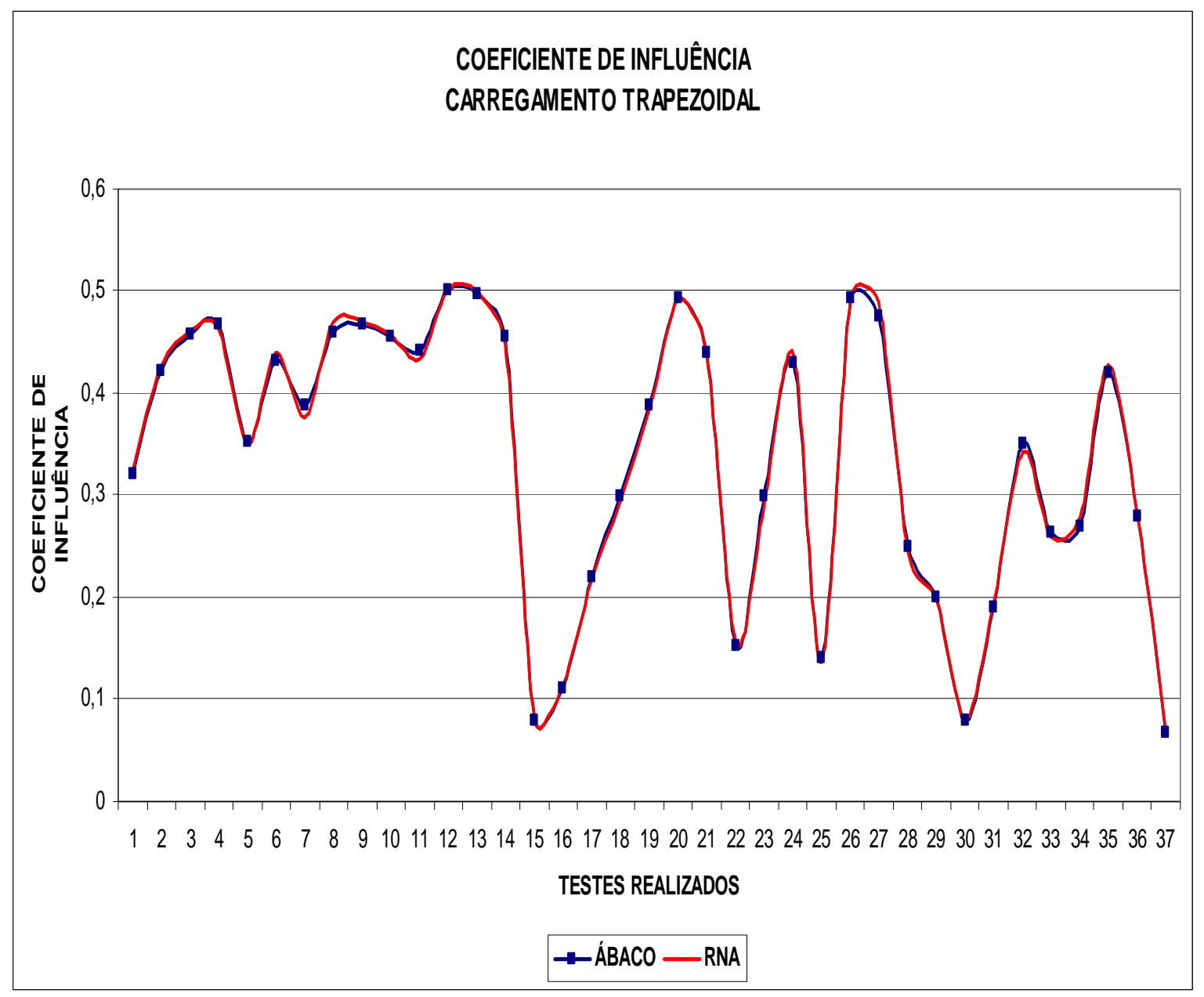

Figura 14. Resultados da RNA para Carregamentos Infinitos Trapezoidais.

ENGEVISTA, v. 9, n. 1, p. 22-34, junho 2007 


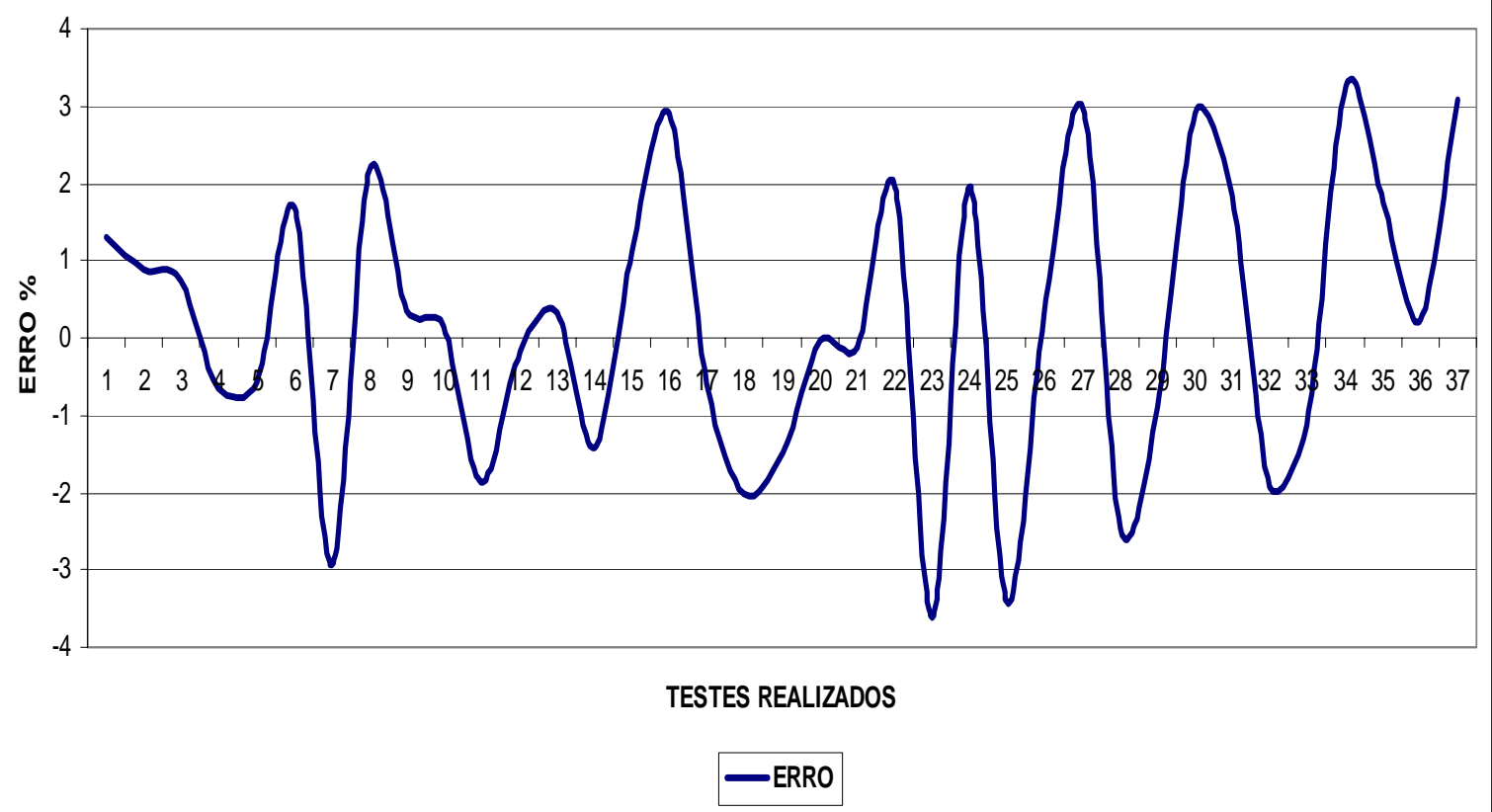

Figura 15. Erro percentual dos resultados da RNA para Carregamentos Infinitos Trapezoidais.

\section{CONCLUSÕES}

O presente trabalho apresentou um estudo sobre a possibilidade de utilização de RNAs na determinação de acréscimos de tensão em um ponto qualquer do maciço de solo, devido à aplicação de sobrecargas triangulares e trapezoidais As formulações apresentadas para a resolução deste tipo de problema geotécnico baseiam-se na Teoria da Elasticidade, com o desenvolvimento de expressões analíticas e gráficas.

Uma comparação entre os resultados fundamentados na Teoria da Elasticidade (solução gráfica) e os resultados obtidos pela RNA (solução computacional) em diversos pontos no interior da massa de solo foi apresentada.

Os resultados desta pesquisa indicam que as RNAs com sua capacidade de responder corretamente a padrões que não tomaram parte do treinamento, aparecem como uma ferramenta adequada para a solução de problemas geotécnicos, mais especificamente no que tange à determinação dos acréscimos de tensões induzidos por carregamentos distribuídos de forma triangular e trapezoidal.

O erro máximo, para os dois tipos de carregamento, foi de cerca de 5\% sugerindo que vale a pena investir nessa ferramenta computacional, estendendo a proposta dessa pesquisa para qualquer tipo de carregamento.

Cabe ressaltar que a qualidade dos resultados obtidos pode ser melhorada não só aumentando-se a quantidade de dados no banco de dados de treinamento, mas também procurando incluir mais padrões, justamente nas zonas de difícil definição e, portanto mais confusas dos ábacos.

Assim, as RNAs aparecem como uma ferramenta capaz de fornecer o coeficiente de influência I, minimizando as dificuldades de obtenção em pontos intermediários dos ábacos.

Finalmente salientamos a importância de testar outros métodos numéricos a serem usados no processo adaptativo, como por exemplo, o método Resiliente de retropropagação de erro.

\section{AGRADECIMENTOS}

Os autores deste trabalho agradecem ao Laboratório de Computação do Programa de Pós Graduação em Engenharia Civil, Labbas/FEN/UERJ, pela disponibilidade de equipamentos. 


\section{BIBLIOGRAFIA}

Boussinesq, J., (1885), Application des Potentiels à l'étude de l'equilibre et du mouvement dês solids elastiques, Paris: Gauthier-Villars.

Dayhoff, J. E. (1990), Neural Network Architectures An Introduction, Van Nostrand Reinhold.

Hagan, M. e Menhaj, M. B., (1994), "Training Feedforward Networks with the Marquardt Algorithm”, IEEE Transactions on Neural Networks, v.5, n.6.

Haykin S., (1994), Neural Networks a Comprehensive Foundation, Macmillan College Publishing Company.

Montoya, P. J., Messeguer, A. G., Cabré, F. M., (1979), Hormigón Armado, ed. Barcelona: Editorial Gustavo Grill.

Osterberg, J.O., (1957), "Influence values for Vertical Stresses im Semi-Infinite Mass Due to Embankment Loading”, Proceedings, Fourth International Conference on Soil Mechanics and Foundation Engineering, Londres, v. 1, p. 393-396.

Poulos, H. e Davis, E. H., (1974), Elastic Solutions for Soil and Rock Mechanics, John Wiley Processing: Explorations in the Microstructure of Cognition. Cambridge: MIT, v.1.

Ranganathan, A., (2004), The LevenbergMarquardt Algorithm. (www.cc.gatech. edu/people/home/ananth/lmtut.pdf).

Roweis, S., (2003), Levenberg Marquardt Optimization, Disponível em (www.cs.toronto.edu/ roweis/notes/lm.pdf).

Souza Pinto, C (2002), Curso Básico de Mecânica dos Solos. São Paulo: Oficina de Textos, 247p.

Suykens, J. A. K., Vandewalle, J. P. L. e de Moor, B. L., (1996), Artificial Neural Networks for Modelling and Control of Non-Linear Systems, Holanda: Kluwer ed.

Zurada, J. M., (1992), Introduction to Artificial Neural Systems, West Publishing Company. 